\title{
Seasonal phytochemical study and antimicrobial potential of Vetiveria zizanioides roots
}

\author{
DELAIR SILVEIRA DOS SANTOS ${ }^{1}$ \\ JÚLIA VIEIRA OBERGER ${ }^{1}$ \\ RIVALDO NIERO ${ }^{1}$ \\ THEODORO WAGNER ${ }^{1}$ \\ FRANCO DELLE MONACHE ${ }^{1}$ \\ ALEXANDRE BELLA CRUZ 1 \\ ZHELMY MARTIN-QUINTAL 2 \\ VALDIR CECHINEL FILHO1,* \\ ${ }^{1}$ Programa de Pós-Graduação em \\ Ciências Farmacêuticas e Núcleo de \\ Investigações Químico-Farmacêuticas \\ (NIQFAR)-Universidade do Vale do \\ Itajaí, 88302-202, Itajaí, SC, Brazil \\ ${ }^{2}$ Universidad Autónoma de Yucatán \\ (UADY) Calle 41 No $421 \times 26$ y 28 \\ Col. Industrial, C.P. 97150, Mérida \\ Yucatán, Mexico
}

\begin{abstract}
This paper describes the seasonal phytochemical variation and the antimicrobial potential of $V$. zizanioides roots collected in Brazil. Considering the high levels of chemical constituents and their biological activity in dichloromethane fraction, the plants were grown in different seasons and the respective dichloromethane fractions were analyzed by gas chromatography-mass spectrometry. The antimicrobial activity was evaluated against several pathogenic microorganisms by determining the minimum inhibitory concentration (MIC) using the agar dilution method. Yields of dichloromethane fractions from plants collected in the autumn and spring occurred in a higher proportion than in other seasons. Khusimol (2) was isolated by column chromatography and identified by NMR and CG-MS, along with other sesquiterpenes, including $\beta$-vetivenene (1), vetiselinenol (3), isovalencenol (4), vetivenic acid (5), $\alpha$-vetivone (6) and $\beta$-vetivone (7). Some extracts showed promising antimicrobial effects, with MICs ranging from 31.25 to $500 \mu \mathrm{g} \mathrm{mL} \mathrm{m}^{-1}$. Kushimol was slightly active against the tested microorganisms.
\end{abstract}

Keywords: Vetiveria zizanioides (Poaceae), seasonality, sesquiterpenes, khusimol, antimicrobial activity

Medicinal plants have emerged as an important source of medicinal agents to treat a variety of diseases, including human infections caused by pathogenic and resistant microorganisms. The search for new medicinal agents against the genera Microsporum and Trichophyton is very important because they are the main agents responsible for dermatophytoses, which are among the most common infectious diseases worldwide and require appropriate treatment $(1,2)$. Vetiveria zizanioides (Linn.) Nash (Poaceae), known as »vetiveria« or »falso-patcholi« in Brazil, is an aromatic and ornamental plant, popularly used for bathing and perfumery. There are several studies indicating its use for therapeutic purpose, and experimental studies have confirmed some of its biological effects $(3,4)$. Several authors have demonstrated its chemical composition, sesquiterpenes being the main com-

\footnotetext{
*Correspondence; e-mail: cechinel@univali.br
} 
ponents in the roots and phenolic compounds in the leaves $(5,6)$. However, little is found in the literature about the species adapted in Brazil. Preliminary studies in our laboratory indicate that crude extracts of this plant act against some pathogenic microorganisms. The present study therefore evaluates the seasonal phytochemical variation, using gas chromatography and the antimicrobial potential of the roots of $V$. zizanioides.

\section{EXPERIMENTAL}

\section{General procedures}

Thin layer chromatography (TLC) was performed on 0.25-mm thick silica gel Merck 60 $\mathrm{F}_{254}$ (Germany) and column chromatography on silica gel 60 (060-0.20 mm, VETEC, Brazil). Spots were visualized under UV light or with sulfuric anisaldehyde, indicative of steroids and terpenes. ${ }^{1} \mathrm{H}$ NMR spectra were recorded at $300 \mathrm{MHz}$ and ${ }^{13} \mathrm{C}$ NMR spectra at $75 \mathrm{MHz}$ using deuterated chloroform as a solvent and tetramethylsilane (TMS) as the internal reference on a Bruker DPX300 apparatus (Bruker, Germany). Chemical shift values are expressed in ppm and coupling constants $(J)$ in Hz. GC-MS analyses were carried out on a Shimadzu GC-MS-QP2010S apparatus (Shimadzu, Japan).

\section{Plant material}

V. zizanioides (Poaceae) roots were collected in the gardens of UNIVALI (Itajaí-SC, Brazil) in December of 2010, April, July and September of 2011. The plant material was authenticated by Prof. Oscar Iza (UNIVALI, Itajaí-Brazil) and a voucher specimen is deposited at the Barbosa Rodrigues Herbarium (Itajaí, Brazil).

\section{Preparation of extracts and fractions}

A hundred grams of roots collected in different months was macerated separately with methanol at room temperature for about two weeks. After solvent removal under reduced pressure using a rotating evaporator, a crude methanolic extract was obtained, which was later used for biological assays and phytochemical analyses. Crude extracts were extracted with dichloromethane. The yields are given in Table I.

\section{Isolation of khusimol}

The methanolic extract of $V$. zizanioides roots collected in autumn $(3 \mathrm{~g})$ was dissolved in dichloromethane giving $2.5 \mathrm{~g}$ of this fraction. The extract was successively chromatographed on a silica gel column eluted with dichloromethane/methanol $(98: 2, V / V)$, resulting in $60 \mathrm{mg}$ of khusimol (2), which was identified by spectroscopic analysis $\left({ }^{1} \mathrm{H}\right.$ - and $\left.{ }^{13} \mathrm{C} \mathrm{NMR}\right)$ in comparison with the literature data (7).

\section{GC-MS analysis}

Samples were analyzed according to the following methodology. Dichloromethane fractions were dissolved in chloroform and a 1- $\mu \mathrm{L}$ aliquot of the solution of each fraction 
was injected into the GC-MS system. GC-MS analysis was performed using an Agilent 7890A (Agilent, USA) series apparatus interfaced with a 5975C mass detector. A HP-HP-5 $(30 \mathrm{~m} \times 0.25 \mathrm{~mm}, 0.10 \mu \mathrm{m})$ dimethylpolysiloxane analytical column was used for the separation. Helium was used as the carrier gas at a flow rate of $1.0 \mathrm{~mL} \mathrm{~min}^{-1}$. The injector (splitless mode, 1:100 split ratio) was maintained at $300^{\circ} \mathrm{C}$. The initial column temperature was set at $50{ }^{\circ} \mathrm{C}$ and kept for $5 \mathrm{~min}$. It was then ramped by $20^{\circ} \mathrm{C} \mathrm{min}^{-1}$ up to $200{ }^{\circ} \mathrm{C}$, then by $20^{\circ} \mathrm{C}$ $\mathrm{min}^{-1}$ up to $290^{\circ} \mathrm{C}$ and, finally, by $20^{\circ} \mathrm{C} \mathrm{min}^{-1}$ up to $310^{\circ} \mathrm{C}$, where it was kept for $15 \mathrm{~min}$. MS detector in a scan $(\mathrm{m} / \mathrm{z}=30$ to $450 \mathrm{Da})$ and positive electron impact ionization (EI) modes were used and data were collected using single ion monitoring (SIM).

\section{Biological assay}

For antimicrobial evaluation, strains from the American Type Culture Collection (ATCC, USA), CEREMIC (C), Centro de Referencia Micológica, Facultad de Ciencias Bioquímicas y Farmacéuticas, Argentina and Control Lab (CL), Brazil, were used. The bacteria used were Bacillus subtilis (ATCC 14579), Escherichia coli (ATCC 11775), Staphylococcus aureus (ATCC 6538P), and Staphylococcus saprophyticus (ATCC 35552. The fungi used were the yeasts Aspergillus fumigatus (ATCC 26934) and Rhizopus sp. (CL 35) and the dermatophytes were Microsporum canis (C 112), Microsporum gypseum (C 115), Trichophyton metagrophytes (ATCC 9972), Trichophyton rubrum (C 137) and Candida albicans (ATCC 10231).

\section{Media and inocula}

The bacteria used were cultivated on Müller-Hinton agar (MHA, Difco, France) at 35 ${ }^{\circ} \mathrm{C}$ for $24 \mathrm{~h}$. Cell suspension in saline $(0.86 \%)$ was adjusted to give a final concentration of $1.5 \times 10^{8}$ cell $\mathrm{mL}^{-1}$, standardized with 0.5 on the McFarland scale $(\lambda=530 \mathrm{~nm})$. The fungi were cultivated on Sabouraud dextrose agar (SDA, Difco). For filamentous fungi, suspensions were obtained according to the reported procedures and were adjusted to the range $1.0 \times 10^{6}$ to $5.0 \times 10^{6}$ spores $\mathrm{mL}^{-1}$ by microscopic enumeration using a hemocytometer. The yeasts were prepared by adjusting the suspension so as to give a final concentration of between $1.0 \times 10^{6}$ and $5.0 \times 10^{6}$ cell $\mathrm{mL}^{-1}$, also standardized with 0.5 on the McFarland scale $(\lambda$ $=530 \mathrm{~nm})$.

\section{Antimicrobial evaluation}

The minimum inhibitory concentration $(M I C)$ was determined for the microorganisms by the agar dilution method, which was carried out on slants $(1 \mathrm{~mL})$. Stock solution of each fraction or khusimol in dimethylsulfoxide (DMSO) was diluted to give serial two-fold dilutions, which were added to each medium (MHA for bacteria and SDA for fungi), resulting in ten different concentrations ranging from 10 to $1000 \mu \mathrm{g} \mathrm{mL} \mathrm{L}^{-1}$. Afterwards, a volume of $1 \mu \mathrm{L}$ of previously prepared inoculum suspension was inoculated with a sterile loop to each slant, with the exception of the sterile control. The antibacterial and antifungal agents, cefoxitin and ketoconazole (both from Sigma, USA) were included in the assay as positive control. The final concentration of DMSO in the assay did not exceed $2 \%$. A drug-free saline solution $(0.86 \%)$ was used as a blank control. The slants were incubated at $35{ }^{\circ} \mathrm{C}$ for the bacteria and yeasts and at $25^{\circ} \mathrm{C}$ for the dermatophyte strains. MICs were visually recorded 
after $24 \mathrm{~h}$ for bacteria and after $48 \mathrm{~h}$ for yeasts, and at a time according to the control fungus growth for the fungi. The experiments were performed in triplicate.

\section{RESULTS AND DISCUSSION}

Table I shows that the yield of methanolic extracts differed between seasons, especially when collected in winter and spring, in which period they were 2 to 4 times higher than in summer and autumn.

Table I. Yield of methanol extract and dichloromethane fraction of V. zizanioides collected in different seasons

\begin{tabular}{cccc}
\hline Season & $\begin{array}{c}\text { Yield of methanolic } \\
\text { extract }^{\mathrm{a}} \\
(\%)\end{array}$ & $\begin{array}{c}\text { Yield of dichloromethane } \\
\text { fraction }^{\mathrm{b}} \\
(\mathrm{g})\end{array}$ & $\begin{array}{c}\text { Yield of dichloromethane } \\
\text { fraction }^{\mathrm{b}} \\
(\%)\end{array}$ \\
\hline Summer & 4.4 & 2.6 & 59.1 \\
Autumn & 3.1 & 2.6 & 83.9 \\
Winter & 10.3 & 8.2 & 79.6 \\
Spring & 14.2 & 11.2 & 78.9 \\
\hline
\end{tabular}

${ }^{a}$ From $100 \mathrm{~g}$ dried roots.

${ }^{\mathrm{b}}$ From methanolic extract.<smiles>CC(C)=C1CC=C2C=CC[C@H](C)[C@]2(C)C1</smiles>

1<smiles>C=C1CCC[C@]2(C)CC=C(C(C)CO)CC12</smiles><smiles>C=C1C2CCC3(C2)C1CCC3C(=O)O</smiles>

5<smiles>CC(C)=C1CCC2=CC(=O)C[C@H](C)[C@]2(C)C1</smiles>

6
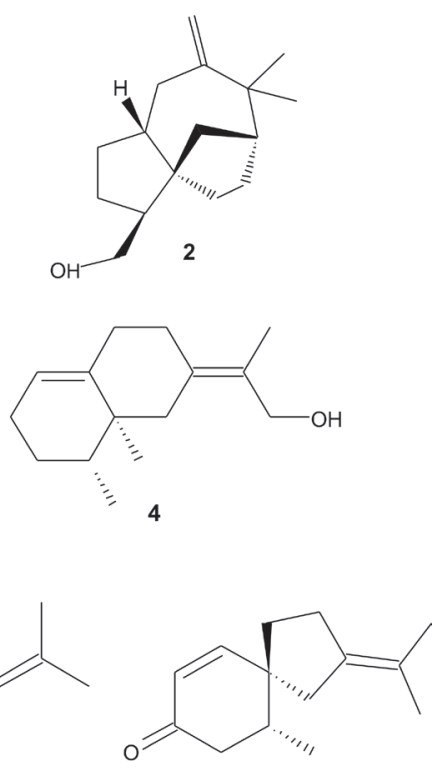

7

Fig. 1. Molecular structures of substances identified in roots of $V$. zizanioides: $\beta$-vetivenene (1), khusimol (2), vetiselinenol (3), isovalencenol (4), vetivenic acid (5), $\alpha$-vetivone (6) and $\beta$-vetivone (7). 
Evaluation by GC-MS evidenced the presence of several components, seven of them identified as $\beta$-vetivenene (1), khusimol (2), vetiselinenol (3), isovalencenol (4), vetivenic acid (5), $\alpha$-vetivone (6) and $\beta$-vetivone (7) in $\mathrm{CH}_{2} \mathrm{Cl}_{2}$ fractions, with compounds 2,4 and 5 being the major compounds (Fig. 1). It is interesting to note that a similar profile of the extracts collected in different seasons was seen. However, plants collected in winter showed significant differences in chemical constitution, both qualitative and quantitative (Fig. 2). For example, the sesquiterpene vetiselinenol (3) appeared only during winter, as well as another compound not yet identified with $t_{\mathrm{R}}$ of $9.55 \mathrm{~min}$ (Fig. 2). The components of the fraction collected in winter were quantified furnishing the following percent yields: 1 (4.1), 2 (8.2), 3 (7.2), 4 (16.7), 5 (17.5), 6 (6.1) and 7 (5.1).

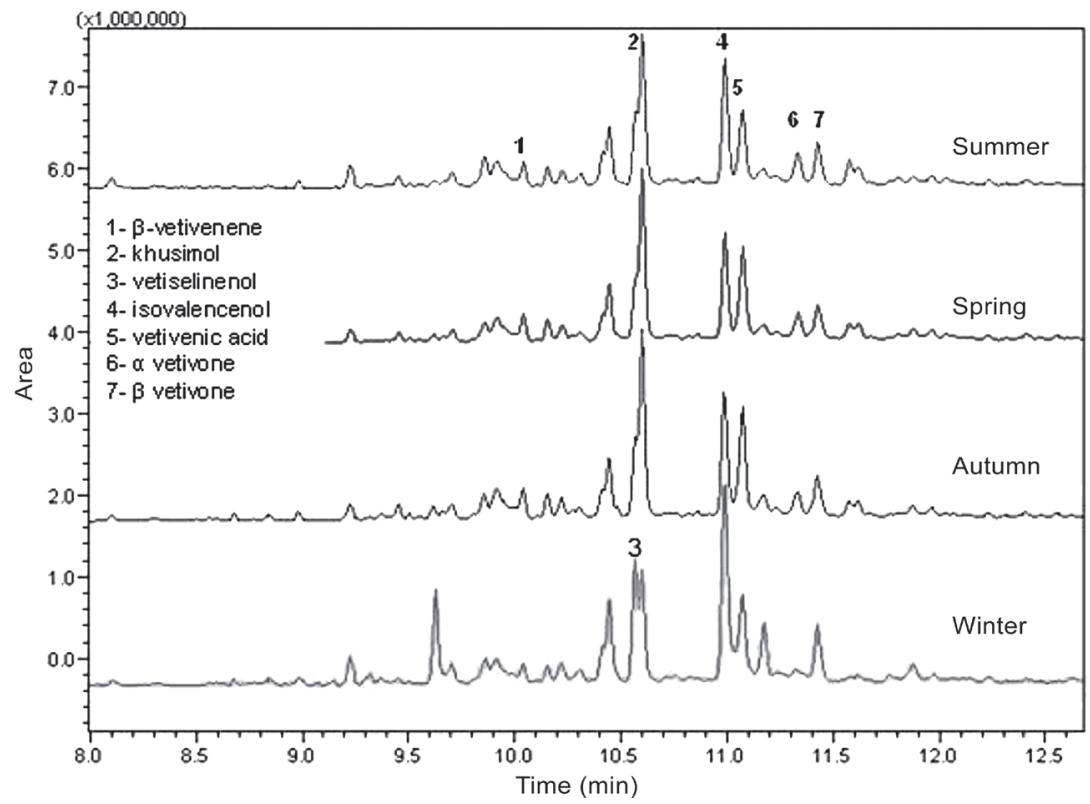

Fig. 2. GC chromatographic profile of dichloromethane fractions collected in different seasons: $\beta$-vetivenene (1), khusimol (2), vetiselinenol (3), isovalencenol (4), vetivenic acid (5), $\alpha$-vetivone (6) and $\beta$-vetivone (7).

Table II shows the antifungal effect of methanolic extracts of roots of $V$. zizanioides collected in different seasons and of the isolated compound khusimol. According the Rios and Recio (8), who suggested good antimicrobial properties for this extract with MIC less than $100 \mu \mathrm{g} \mathrm{mL} \mathrm{L}^{-1}$, all the evaluated extracts were promising against Microsporum canis, Microsporum gypseum, Trichophyton mentagrophytes and Trichophyton rubrum with MIC values between 62.5 and $31.25 \mu \mathrm{g} \mathrm{mL}^{-1}$. Khusimol, one of the major compounds in all extracts, was weakly active against these fungi, suggesting that the antifungal potential was related to the presence of other substances or the occurrence of synergic effects.

Table III indicates that, in general, the extract of $V$. zizanioides collected in winter exerted the most promising antimicrobial effects. This fact may be related to the presence of 
D. S. Dos Santos et al.: Seasonal phytochemical study and antimicrobial potential of Vetiveria zizanioides roots, Acta Pharm. 64 (2014) 495-501.

Table II. Minimal inhibitory concentration of methanolic extracts of V. zizanioides collected in different seasons, khusimol and ketoconazole against pathogenic microorganisms

\begin{tabular}{lccccccc}
\hline & \multicolumn{7}{c}{$M I C\left(\mu \mathrm{g} \mathrm{mL} \mathrm{mL}^{-1}\right)$} \\
\cline { 2 - 8 } Sample & $\begin{array}{c}M . \\
\text { canis }\end{array}$ & $\begin{array}{c}M . \\
\text { gypseum }\end{array}$ & $\begin{array}{c}\text { T. meta- } \\
\text { grophytes }\end{array}$ & $\begin{array}{c}\text { T. } \\
\text { rubrum }\end{array}$ & A.fumigatus & $\begin{array}{c}\text { Rhizopus } \\
\text { sp }\end{array}$ & $\begin{array}{c}\text { C. } \\
\text { albicans }\end{array}$ \\
\hline Summer & 62.5 & 62.5 & 62.5 & 31.25 & 500 & $>1000$ & 500 \\
Autumn & 62.5 & 31.25 & 31.25 & 31.25 & 1000 & $>1000$ & 500 \\
Winter & 62.5 & 31.25 & 31.25 & 31.25 & $>1000$ & $>1000$ & 1000 \\
Spring & 62.5 & 62.5 & 62.5 & 31.25 & $>1000$ & $>1000$ & 250 \\
Khusimol & 500 & 250 & $>1000$ & $>1000$ & $>1000$ & 500 & 500 \\
Ketoconazole & 8 & 6 & 8 & 3 & 7 & 15 & 0.3 \\
\hline
\end{tabular}

DMSO - negative control, inactive.

Table III. Minimal inhibitory concentration $\left(\mu \mathrm{g} \mathrm{mL}^{-1}\right)$ of dichloromethane fractions of $\mathrm{V}$. zizanioides collected in different seasons and khusimol against pathogenic bacteria

\begin{tabular}{lcccc}
\hline \multirow{2}{*}{ Sample } & \multicolumn{4}{c}{ MIC $\left(\mu \mathrm{gL} \mathrm{mL}^{-1}\right)$} \\
\cline { 2 - 5 } & S. aureus & S. saprophyticus & B. subtilis & E. coli \\
\hline Summer & 500 & 250 & 250 & 500 \\
Autumn & $500-250$ & 250 & 250 & 1000 \\
Winter & 250 & 125 & 500 & 500 \\
Spring & $500-250$ & 125 & 500 & 500 \\
Khusimol & 500 & 250 & $>1000$ & $>1000$ \\
Cefoxitin & 2 & 4 & 1 & 4 \\
\hline
\end{tabular}

DMSO - negative control, inactive.

vetiselinenol (3) and other compounds, such as that with $t_{\mathrm{R}}$ of $9.55 \mathrm{~min}$, or to the additive and/or synergistic effects (9).

Considering that sesquiterpenes are the major compounds of these extracts, as evidenced by chromatographic analyses and previous investigations of this plant (10). As can be seen, all the fractions exhibited only moderate or weak effects, with E. coli being the most resistant microorganism tested. Barros and co-workers (10) studied the antibacterial effects of essential oil of $V$. zizanioides collected in winter in another region of Brazil and demonstrated it to be a little more active than our dichloromethane fraction against $S$. aureus, with MIC of $150 \mu \mathrm{g} \mathrm{mL} \mathrm{g}^{-1}$. They also found bioactivity against other microorganisms, including Bacillus cereus and Micrococcus roseus (MIC $190 \mu \mathrm{g} \mathrm{mL}^{-1}$ ). On the other hand, they evidenced that the crude ethanolic extract or dichloromethane fractions were much less active than the essential oil. However, dichloromethane fractions from our study showed higher activity, probably due to the significant difference in the chemical composition of extracts. 


\section{CONCLUSIONS}

In conclusion, our results show that $V$. zizanioides exhibits a promising antimicrobial potential, especially against dermatophytes and C. albicans, a fungus that is very resistant to the action of extracts of vegetable origin. Kushimol, one of the main identified compounds, was slightly active against the tested microorganisms, suggesting other bioactive compounds or additive/synergistic effects.

\section{REFERENCES}

1. M. P. De Campos, V. Cechinel Filho, R. Z. Da Silva, R. A. Yunes, S. Zacchino, S. Juarez, R. C. B. Cruz and A. Bella Cruz, Evaluation of antifungal activity of Piper solmsianum C. DC. var. solmsianum (Piperaceae), Biol. Pharm. Bull. 28 (2005) 1527-1530; DOI: 10.1248/bpb.28.1527.

2. K. E. Machado, V. Cechinel Filho, R. C. B. Cruz, C. Meyre-Silva and A. Bella Cruz, Antifungal activity of Eugenia umbelliflora against dermatophytes, Nat. Prod. Commun. 4 (2009) 1181-1184.

3. S. K. Karan, D. Pal, S. K. Misha and A. Mondal, Antihyperglycaemic effect of Vetiveria zizanioides (L.) Nash root extract in alloxan induced diabetic rats, Asian J. Chem. 25 (2013) 1555-1557; DOI: 10.14233/ajchem.2013.13137.

4. J. Prajna, J. Richa and C. Dipjyoti, HPLC quantification of phenolic acids from Vetiveria zizanioides (L.) Nash and its antioxidant and antimicrobial activity, J. Pharm. 2013, 1-6; DOI: $10.1155 / 2013 / 270472$.

5. P. Champagnat, A. Heitz, A. Carnat, D. Fraisse, A. P. Carnat and J. L. Lamaison, Flavonoids from Vetiveria zizanioides and Vetiveria nigritana (Poaceae), Biochem. Syst. Ecol. 36 (2008) 68-70; DOI: 10.1016/j.bse.2007.05.015.

6. L. Paillat, C. Périchet, J. P. Pierrat, S. Lavoine, J. J. Filippi, U. Meierhenrich and X. Fernandez, Purification of vetiver alcohols and esters for quantitative high-performance thin layer chromatography determination in Haitian vetiver essential oils and vetiver acetates, J. Chromatog. A 1241 (2012) 103-111; DOI: 10.1016/j.chroma.2012.04.012.

7. R. C. Rao, I. Granger, J. Gleye, J. M. Angereau and C. Bessibes, Khusimol, a non-peptide ligand for vasopressin V1a receptors, J. Nat. Prod. 57 (1994) 1329-1335; DOI: 10.1021/np50112a001.

8. J. L. Rios and M. C. Recio, Medicinal plants and antimicrobial activity, J. Ethnopharmacol. 22 (2005) 80-84; DOI: 10.1016/j.jep.2005.04.025.

9. H. Wagner and G. Ulrich-Merzenich, Synergy research: approaching a new generation of phytopharmaceuticals, Phytomedicine 16 (2009) 97-110; DOI: org/10.1016/j.fitote.2010.11.016.

10. G. C. Barros, L. M. F. Tresvenzol, L. C. Cunha, P. H. Ferri, J. R. Paula and M. T. F. Bara, Composição química, atividade antibacteriana e avaliação da toxicidade aguda de Vetiveria zizanoides L. Nash (Poaceae), Latin Am. J. Pharm. 28 (2009) 531-537. 